\title{
Towards Globalisation of a Profession
}

\author{
Sandra Ouellette, MEd, CRNA, FAAN and Betty J. Horton, PhD, CRNA \\ International Federation of Nurse Anaesthetists Committee, Switzerland
}

\begin{abstract}
The International Federation of Nurse Anesthetists (IFNA) has been striving to promote quality education and practice standards since it began in 1989. Many organisations throughout the world have recognised these efforts including the International Council of Nurses. This article summarises IFNA's achievements and introduces IFNA's new initiative to enhance the quality of anaesthesia care worldwide through an approval process for education programmes.

KEY WORDS: International anesthesia education standards; International anesthesia practice standards; Approval on non-physician anesthesia programs worldwide
\end{abstract}

$\mathrm{T}$ The 9th World Congress for Nurse Anesthetists was held from June 4 to June 7, 2010, in The Hague, The Netherlands. During the meeting, participants celebrated the 20th Anniversary of The International Federation of Nurse Anesthetists (IFNA) and witnessed the launch of the Anesthesia Program Approval Process (APAP). This process along with the appointment of a new IFNA Practice Committee completes all the action steps necessary for the globalisation of a profession. IFNA has much to be proud of.

This article begins with a brief history of the development of IFNA. Action steps towards globalisation of a profession are identified and briefly discussed. The history of IFNA's search for the most appropriate process

Correspondence to: Manda Dunne, BARNA Representative for IFNA, Theatres, Queen Elizabeth Hospital, Stadium Road, Woolwich SE184QH, London. for quality assurance in international education and practice precedes a description of the Anesthesia Program Approval Process. The article concludes with a call to promote quality assurance standards for nurse anaesthesia education and practice throughout the world.

\section{DEVELOPMENT AND PURPOSE OF THE INTERNATIONAL FEDERATION OF NURSE ANESTHETISTS}

The IFNA began on June 10, 1989, when 11 representatives from countries throughout the world signed the charter. Today, there are 35 countries that are IFNA members. The vision, mission and objectives of IFNA are as follows (International Federation of Nurse Anesthetists, 1999):

\section{IFNA's vision}

The IFNA is the authoritative voice for nurse anaesthetists and nurse anaesthesia, supporting and enhancing quality anaesthesia worldwide. As professionals, nurse anaesthetists are recognised for their significant contribution to global health care as nurses, practitioners, teachers, administrators, researchers and consultants. The IFNA participates in the formulation and implementation of healthcare policy and the recognition of nurse anaesthetists as essential and cost-effective healthcare providers.

\section{IFNA's mission}

IFNA is an international organisation representing nurse anaesthetists serving the public and its members. The mission of the federation is dedicated to the precept that its members are committed to the advancement of educational standards and practices which will advance the art and science of anaesthesiology and thereby support and enhance 
quality anaesthesia care worldwide. The IFNA establishes and maintains effective cooperation with institutions that have a professional interest in nurse anaesthesia.

\section{Objectives of IFNA}

1. To promote cooperation between nurse anaesthetists internationally.

2. To develop and promote educational standards in the field of nurse anaesthesia.

3. To develop and promote standards of practice in the field of nurse anaesthesia.

4. To provide opportunities for continuing education in anaesthesia.

5. To assist nurse anaesthetists' associations to improve the standards of nurse anaesthesia and the competence of nurse anaesthetists.

6. To promote the recognition of nurse anaesthesia.

7. To establish and maintain effective cooperation between nurse anaesthetists, anaesthesiologists and other members of the medical profession, the nursing profession, hospitals and agencies representing a community of interest in nurse anaesthesia.

\section{ACTION STEPS FOR ESTABLISHING A GLOBAL PROFESSION}

At the IFNA World Congress in Austria in 1997, Dr Marjorie Peace Lenn, Executive Director of the Center for Quality Assurance in International Education, outlined five steps for establishing a global profession Caulk [2001]. They are as follows:

1. Act as an international witness for the need for professional standards in anaesthesia;

2. Interact effectively with appropriate regional and international organisations;

3. Act as a liaison to other global professions;

4. Monitor and record its own progress through research, publication and international forums;

5. Consider the development of an IFNA quality assurance programme for nurse anaesthesia educational and professional development programmes.

The first action step to develop international professional anaesthesia standards began in 1989 very soon after IFNA was chartered. IFNA Educational Standards for Preparing Nurse Anesthetists [International Federation of Nurse Anesthetists, 1990] were developed by the IFNA Education Committee and adopted by the Council of National Representatives on June 1, 1990. They were revised on June 23, 1999.
IFNA Standards of Practice [International Federation of Nurse Anesthetists, 1991] were developed also by the Education Committee and approved by the Council of National Representatives on June 17, 1991. These standards were revised on May 18, 1996. The IFNA Code of Ethics [International Federation of Nurse Anesthetists, 1992] was adopted in May 1992 and Patient Monitoring Guidelines, later changed to Patient Monitoring Standards [International Federation of Nurse Anesthetists, 1998] were adopted in June 1998.

The second and third action steps towards globalising the profession have also been accomplished. Throughout its existence, IFNA has interacted with appropriate regional and international organisations. Examples of groups with which IFNA has had liaison include: European Economics Committee; World Health Organization, Center for Quality Assurance in International Education; World Federation of Societies of Anesthesiologists; International Hospital Federation; International Society for Quality in Health Care; and the International Council of Nurses (ICN). IFNA is recognised as one of seven affiliate members of ICN. IFNA's international standards on education, practice and monitoring and the Code of Ethics have been endorsed by the ICN since 2002. IFNA stands ready to interact with any profession wishing to become a global profession.

The fourth action step to monitor the organisation's progress has been achieved through international research, publications and meetings. For example, an extensive worldwide study of practice, education and legislation about nurse anaesthesia was conducted by Dr Maura McAuliffe and Dr Beverly Henry with input from the World Health Organization between 1996 and 1999 [McAuliffe and Henry, 1999]. The study demonstrated the following: nurses administer anaesthesia in 106 countries; nurses provide anaesthesia in $77 \%$ of rural areas of the world and in $75 \%$ of urban areas; $57 \%$ reported that they were required to have a physician anaesthesiologist supervise their work; all had a formal educational programme but some had to leave their countries to become educated; $50 \%$ reported that continuing education was not available; $74 \%$ reported that hospital policies as well as governmental regulations guide the practice of nurse anaesthesia.

There have been numerous publications about IFNA and the organisation has conducted two symposiums and seven world congresses: Lucerne, Switzerland, 1985; Amsterdam, The Netherlands, 1988; Oslo, Norway, 1991; Paris, France, 1994; Chicago, Illinois, 2000; Helsinki, Finland, 2002; Lausanne, Switzerland, 2006; and The Hague, The Netherlands in 2010. 
The fifth and final action step to globalise nurse anaesthesia as a profession was taken at the 9th World Congress of Nurse Anesthetists in 2010, when the Council of National Representatives appointed a new Practice Committee and IFNA launched the APAP. The purposes of the Practice Committee will be as follows: to define the scope of practice of nurse anaesthetists and other non-physician anaesthesia providers in member and non-member countries; to identify the credentials necessary to practise as a nurse anaesthetist in various countries and identify the regulatory bodies responsible for credentialling; to identify various payment models for anaesthesia services in various countries; to develop a model for continuing education and lifelong learning for countries with interest in this process; to review and revise Practice Standards and Ethical Standards as necessary; and to recommend speakers and topics to the Congress Planning Committee for future congresses.

\section{ANESTHESIA PROGRAM APPROVAL PROCESS}

Interest in international quality assurance for anaesthesia education was confirmed in 1998 when the IFNA Education Committee proposed formal processes for both education and practice. Discussions on the issue were held at the 2000 World Congress in Chicago and 2001 IFNA Board of Officers meeting. A presentation by the Chair of USA's COA (Council on Accreditation of Nurse Anesthesia Educational Programs) during the 2002 World Congress in Helsinki provided IFNA with several options to consider on how to approve education programmes while taking cultural, national or regional differences into consideration.

The first draft of an application process was developed in 2006-2007 by IFNA's Education Committee members from Switzerland, Africa, Taiwan, Sweden and the United States. As part of this process, four anaesthesia education programmes located in Sweden, The Netherlands, Switzerland and the United States completed a pilot project and were awarded 'IFNA Recognition' in 1998. The process resulting in the official APAP included revisions based on results from the pilot project, a call for public comments, feedback from internal and external parties, and final approval of the documents and process by IFNA decision-making bodies in 2010. APAP is based on IFNA's belief that nurses should be appropriately educated if they are utilised for pre-operative or postoperative preparation of the patient and if they perform venous and arterial cannulations, induction and emergence of anaesthesia, intubation and extubation, and if they are left alone for any reason [Caulk, 2001]. APAP addresses IFNA's concern that nurse education throughout the world is sufficient to support anaesthesia practice and patient safety by asking programmes to strive to meet global education standards.

\section{Categories of approval}

APAP [International Federation of Nurse Anesthetists, 2010] is designed to work with non-physician anaesthesia programmes as they currently exist if they pledge to meet IFNA's Education Standards to the best of their abilities. Three categories of approval are available: registration, recognition and accreditation; only one type will be awarded to a programme at any given time. Offering three categories of approval recognises (1) the diversity of nurse anaesthesia programmes throughout the world; (2) the economic stage of development of a country; (3) the resources available to individual programmes; (4) a commitment of diverse programmes to a common standard of educational quality.

Each of the three categories requires a pledge to comply with IFNA's Education Standards and the signatures of the program director and the highest institutional official. Registration simply requires signatures and the pledge while Recognition includes an additional curriculum audit to determine if it contains the elements of the curriculum portion of IFNA's Education Standards. No fees are charged for Registration or Recognition. Programmes interested in seeking accreditation must submit a written self-study, host an on-site visit by IFNA representatives and pay expenses. Successful programmes in all three categories are recognised by having their curriculums posted on IFNA's website and receiving certificates of achievement.

\section{Eligibility}

Eligibility for approval or continued approval at 5-year intervals is as follows:

- The anaesthesia programme educates non-physicians.

- Admission requirements for IFNA Registration or IFNA Recognition include an education in nursing or another scientific background that prepares a student to succeed in the anaesthesia education programme.

- Admission requirements for IFNA Accreditation include an education in nursing that prepares a student to succeed in the programme.

- There is official evidence from a governmental entity that the programme is currently authorised, recognised, chartered, audited, accredited or has some equivalent official status in the country, if available. 
- There is evidence that the programme has not been denied approval, recognition or accreditation by a governmental or non-governmental accreditation or quality assurance entity. (This requires the signature of a programme official for confirmation.)

\section{Inclusive process}

IFNA believes that it is possible to improve the health and welfare of humanity by promoting international educational standards for non-physician anaesthesia programmes. Based on this belief and for the purposes of programme approval, it is the policy of IFNA to approve programmes that admit students who are nurses or who are educated in another scientific area that prepares students to succeed in their anaesthesia education. Although IFNA strongly supports a nursing background for admission, it also believes in an approval process that recognises the differences that currently exist in the educational preparation of health professionals worldwide that have contributed to nurses and non-nurses being enrolled in anaesthesia programmes. IFNA believes that an inclusive process provides the greatest opportunity to improve anaesthesia care to patients now and in the future [International Federation of Nurse Anesthetists, 2010]. Resources are available on IFNA's website at www.ifna-int.org regarding information for those interested in learning more about APAP or completing applications.

\section{SUMMARY}

In summary, IFNA has promoted the globalisation of practice and education standards since it was chartered. The recent inauguration of a Practice Committee and of APAP, and an approval process for non-physician anaesthesia programmes are examples of this commitment. It is expected that the IFNA Education Committee and Practice Committee will work together to increase the visibility of nurse anaesthetists internationally as well as moving towards ongoing improvement of anaesthesia care through the continued standardisation of nurse anaesthesia as a global profession.

\section{REFERENCES}

Caulk RF. International Federation of Nurse Anesthetists. In: Foster SD and Faut-Callahan M (eds). A Professional Study and Resource Guide for the CRNA. Park Ridge, IL: AANA Publishing, Inc., 2001, 398-399.

International Federation of Nurse Anesthetists. Code of Ethics, 1992.

International Federation of Nurse Anesthetists. IFNA Standards of Practice, 1991 with 1996 revisions.
International Federation of Nurse Anesthetists. Patient Monitoring Guidelines, 1998.

International Federation of Nurse Anesthetists. IFNA Educational Standards for Preparing Nurse Anesthetists, 1990 with 1999 revisions.

International Federation of Nurse Anesthetists (1999). Available at: http://www.ifna-int.org/ifna/page.php?
About IFNA. Accessed 19 August 2010.

International Federation of Nurse Anesthetists. Anesthesia Program Approval Process (APAP) Operational Policies and Procedures, 2010.

McAuliffe MS, Henry B. Nurse anesthesia world-wide: an analysis of practice, education and legislation. Research Report, 1999. 